\title{
Neurobiochemical Roles of Low Molecular Weight Antioxidants on Oxidative Stress Biomarkers and Severity of Ischemic Stroke in Wistar Rats
}

\author{
Nasiru $\mathrm{S}^{*}$, Bulama $\mathrm{I}^{2}$, Abdurrahman $\mathrm{JH}^{1}$, Abubakar $\mathrm{NA}^{3}$, Salisu $\mathrm{AB}^{4}$, Salisu $\mathrm{B}^{5}$, Abbas $\mathrm{AY}^{6}$, Yusuf $\mathrm{S}^{6}$, and \\ Suleman $\mathrm{BL}^{6}$ \\ ${ }^{1}$ Department of Veterinary Physiology and Biochemistry, Nigeria \\ ${ }^{2}$ Department of Veterinary Physiology, Pharmacology and Biochemistry, University of Maiduguri, Nigeria \\ ${ }^{3}$ Department of Chemical Pathology, Faculty of Medical Laboratory Sciences, Nigeria \\ ${ }^{4}$ Department of Medicine, College of Health Science, Nigeria \\ ${ }^{5}$ Department of Veterinary Surgery and Radiology, UsmanuDanfodiyo University Sokoto, Nigeria \\ ${ }^{6}$ Department of Biochemistry, Nigeria
}

Corresponding author: Nasiru S, Department of Veterinary Physiology and Biochemistry, Nigeria, Tel: +2348030411807, E-mail: suleiman.nasiru@udusok.edu.ng

Citation: Nasiru S, Bulama I, Abdurrahman JH, Abubakar NA, Salisu AB, et al. (2018) Neurobiochemical Roles of Low Molecular Weight Antioxidants on Oxidative Stress Biomarkers and Severity of Ischemic Stroke in Wistar Rats. J Neurol Neurol Disord 4(1): 101

Received Date: November 16, 2017 Accepted Date: January 23, 2018 Published Date: January 25, 2018

\begin{abstract}
Purpose: To evaluate the neurobiochemical role(s) of low molecular weight (LMWA) antioxidants in the treatment of surgicallyinduced ischemic stroke (IS) in wistar rats.

Methods: Ischemic stroke was induced in wistar rats using middle cerebral artery occlusion (MCAO). Neurological assessments were carried out using stair case, cylinder test and modified neurological severity score (mnss) methods. Low molecular weight antioxidants (vitamins C, E, $\alpha$-lipoic acid, dimethyl sulfoxide and mannitol) were orally administered to the rats for two weeks in three different doses $(22.5,45$ and $67.5 \mathrm{mg} / \mathrm{kg})$. Serum and brain tissue homogenate of the animals were then assessed for antioxidants and oxidative stress biomarkers (SOD, CAT, GPX activities and MDA concentrations) respectively.

Results: Significant increase $(\mathrm{P}<0.05)$ in the antioxidant enzymes activities and significant $(\mathrm{P}<0.05)$ reduction of MDA concentration in the groups treated with low molecular weight antioxidants (LMWA) in a dose dependent manner.

Conclusion: It can be concluded from this study that LMWA reduces oxidative stress in surgically-induced ischemic stroke rats and underscores relevance of the role of LMWA in the treatment of IS rats.

Keywords: Neurochemical; Ischemic stroke; Middle cerebral artery occlusion; Low molecular weight antioxidant; Oxidative stress

List of Abbreviations: IS: Ischemic stroke; MCAO: Middle cerebral artery occlusion; mNSS: Modified neurological severity score; LMWA: Low molecular weight antioxidants; ROS: Reactive oxygen species; SOD: Super oxide dismutase; CAT: Catalase; GPX: Glutathione peroxidase; MDA: Malondialdehyde; PBS: Phosphate buffer saline; BW: Body weight; SINT: Stroke induced but not treated; NSINT: Non-stroke induced and non-treated
\end{abstract}

\section{Introduction}

The most common cause of disability according to the World Health Organization is stroke, each year 15 million individuals suffer from stroke in the world. Of these, 5 million surrender and an additional 5 million are permanently disabled [1]. Ischemic stroke is the most common type of stroke accounting for about $88 \%$ of all neurological cases; which is as a result of brain being denied blood supply denying the brain oxygen and glucose, thereby instigating the ischemic cascade [2]. Excessive generation of free radicals like reactive oxygen species (ROS) and the impairment of endogenous antioxidants defense mechanisms such as superoxide dismutase (SOD), catalase (CAT) and glutathione peroxidase (GPX) begin immediately after the onset of IS. These result in secondary events like tissue hypoxia and cellular dysfunction, consequently, resulting in neuronal malfunction and death $[3]$.

The mechanism and pathogenesis of ischemic injury include; excitotoxicity, oxidative stress (OS), inflammation and apoptosis [47]. In addition, OS plays a key role in the mechanism and pathogenesis of ischemic/reperfusion injury [5]. During ischemic injury, 
neuron and glial cells are destroyed due to the overproduction of free radicals; and this interacts with important biomolecules such as nucleic acids, lipids and proteins [6]. Because of high oxidative metabolic activity, extreme production of ROS, the neurons non replicating nature and also a high membrane-to-cytoplasm ratio, the brain is therefore vulnerable to oxidative stress $[7,8]$. Other sources of lipid peroxidation reactions in the brain are high levels of polyunsaturated fatty acids in the membrane lipids and transition metals such as iron, and these are capable of catalyzing the production of reactive radicals in the brain [9-10]. Lipids and Apart from proteins that are classical target of free radicals attack, gene transcriptional processes associated with pathologic events are also there target such as activator protein-1 and nuclear factor-kB, both of which are activated by free radicals [11-12]. The brain uses enzymatic metabolism as the major defense mechanism to combat reducing its severity [13]. Antioxidants reduce the severity of oxidative stress either by forming a less active radicals or by quenching the damaging free radical chain reactions on macromolecules such as proteins, lipids, carbohydrates or DNA by been oxidize itself [14-16].

The frequency of stroke hospitalization in Africa ranges from $0.9 \%-4.0 \%$ as documented, it accounted for $0.5 \%-45 \%$ of all cases of neurological admissions and have been reported to be the eight leading cause of death in Nigeria among other diseases [17]. It was discovered in Africa, that the liability of the extended hospitalization on the family of stroke patients, the consequences of incapacity from the IS injury, and the economic indication on survival of stroke patients as well as the overstretching of hospital facilities have been previously studied [18]. And it was discovered that; most of the people lives in rural areas, where underdevelopment due to poverty, socialism, unavailability and inaccessibility to good and qualitative health care have played major roles in tendency, management and prognosis of stroke [19].

Worldwide, it was found that stroke is the most common cause of incapacity and the second leading cause of death [20]. So many researches have been conducted and reported on the objective of understanding the pathophysiology of cerebral ischemia but therapeutic options still remain very limited [21]. Regrettably, little therapeutics has been known to treat IS. Currently, the only FDA approved drug for stroke patient's treatment is the tissue plasminogen activator (tPA). However, due to its slight therapeutic window of less than $4.5 \mathrm{~h}$ and safety margins, only less than $5 \%$ of patients can benefit from this medication [22]. In view of this, more new approaches are needed in the treatment of stroke. Thus, the study was designed to study the neurochemical potentials of low molecular weight antioxidants in the treatment of Wistar strain rats surgically induced with ischemic stroke.

\section{Materials and Methods}

\section{Animals and Treatment}

One hundred (100) apparently healthy rats of Wistar strain weighing between 180 and 200g were obtained from the Animal House of the Department of Veterinary Physiology and Biochemistry, Faculty of Veterinary Medicine, Usmanu Danfodiyo University, Sokoto, Nigeria. The Ethics Committee of the Department of Veterinary Physiology and Biochemistry approved the animal experiment with ethical clearance number $\mathrm{VPB} / \mathrm{EC} / 17 / 16$. The rats were housed under a standard conditions at room temperature of $35-37.5^{\circ} \mathrm{C}$ and were subjected to a 12-hour light/12-hour dark cycle. They were fed with grower's mash of vital ${ }^{\circledR}$ feed $a d$-libitum, randomly divided into eight groups as stroke induced and treated with vitamin $\mathrm{C}$, vitamin E, uric acid, alpha lipoic acid, dimethyl sulfoxide and mannitol (VC, VE, UA, ALA, DMSO, Man) respectively. The two other groups were stroke induced non-treated and non-stroke induced non-treated (SINT, NSINT).

\section{Stroke Induction}

The focal cerebral ischemic model was conducted using MCAO method as described by Sprat et al. [23]. IS was induced in this study by occluding the middle cerebral artery (MCA) in wistar rats. Ketamine and Xylazine at the dose of $80 \mathrm{mg} / \mathrm{kg}$ and $5 \mathrm{mg} / \mathrm{kg}$ body weight respectively were used to anesthize the rats. The anesthetic condition was maintained until the end of the occluding period. The neck regions of the rats were shaved and scrubbed with savlon ${ }^{\oplus}$, incision was done at the scrubbed area to gain access to the common carotid artery (CCA). The artery was ligated proximally, a niche incision was created on the CCA distally using $25 \mathrm{G}$ needle, a silicon-coated suture with the diameter and length of $0.35 \mathrm{~mm}$ and $5 \mathrm{~mm}$, respectively was manipulated through the external and internal carotid arteries to block the MCA. The incisions made were closed using a non-absorbable suture material (nylon) and the rats were allowed to recover from the anesthetic condition in the cages. During the induction, the heart rate and rectal temperatures were monitored.

\section{Neurological Assessments}

\section{Modified Neurological Severity Score (mNSS)}

Before and after treatment of the rats, mNSS was used to examined the level of IS and progress in the treatment in various groups. This method was performed following the method of Chen et al. [24]. The total score of 18 points consisting of five components: consciousness and respiration, cranial nerve function, motor function, sensory function and coordination. Eighteen different tasks were used to evaluate these functions. One point was given for failure to perform a task and zero for successful performance of the task. Scores ranged from zero in healthy uninjured rats to a maximum of 18 indicating severe neurological dysfunction with failure in all tasks. The mNSS immediately after stroke reflects the initial severity of injury. Immediately after the initial evaluation of mNSS the rats were assigned to different treatment groups. 


\section{Beam Walking Test (BWT)}

Beam test was carried out using the method reported by Jover et al. [25]. A wooden beam (1m in length, $1.5 \mathrm{~cm}$ in diameter) was placed $60 \mathrm{~cm}$ above the floor between the animal's room and a starting point. Each rat was placed on the beam at the starting point and allowed to walk in the direction of the room; every successful rat would walk into its room in 20s. Failure to reach the destination or falling (tumbling) from the beam is recorded as motor-coordination deficit. Experimental rats were graded as follows; those that crossed in 20s were scored 5, those that crossed in $25 \mathrm{~s}$ were scored 4 , those that crossed in 30 s were scored 3 , while those that fell down or fail to move got 0 and 1 respectively.

\section{Staircase Test (SCT)}

This test was conducted by modifying the method of Baird et al. [26] in order to assess the independent use of the forelimbs of the rats. It was performed by placing the experimental rat on a wooden staircase and placing feed on the topmost step. The staircase is comprised of five steps and each step is scored 1 point with maximum of 5points for any rats that was able to get to the top. Food deprivation and daily pre-training was done for four weeks prior to the experiment so as to make the experimental rats get familiar to the test.

\section{Cylinder Test (CT)}

Cylinder test was carried out on the experimental rats to investigate the neural basis of spatial and motor behavior. The method reported by Gharbawie et al. [27] was modified by constructing a locally made glass cylinder and used to carry out the test. The rats were placed in the cylinder and were observed; the light was put off so as to allow the rats to explore better, 1 point was scored for standing for 5 seconds inside the cylinder and up to the maximum of 5 points for standing for 5 minutes.

\section{Blood Sample Collection}

Following the two weeks of the antioxidants supplementation to the experimental rats, blood samples were collected from the rats through cardiac puncture. The rats were anesthetized using chloroform in a glass jar. After proper anesthesia, the rats were laid on their back, an index finger was placed at the level of the lowest ribs without pressure been applied, the heart was located around this area, just about $1 \mathrm{~cm}$ above the last ribs approximately. A syringe at an angle of 45 degree was held, the needle was inserted between the intercostal muscles to gain access to the heart. Blood was drawn, immediately poured into plain tubes and spun using bench top centrifuge at $3000 \mathrm{rpm}$ for 5 minutes using bench top centrifuge, the supernatant was removed and stored at $-20{ }^{\circ} \mathrm{C}$ until required for analyses for oxidative stress indices.

\section{Brain Tissue Extraction and Homogenization}

This was done according to the method of Rezanejad et al. [28]. Micro dissecting scissors was used to open the skin at the midline of the head of the rats, cutting from the roof of the skull to the mid-eye area, scissors was used to fold back the skin flaps, and the skull was then cut at the midline fissure without cutting into the brain tissue. The raised skull cap was removed with the curved forceps, applying slight pressure. The brain was then released from the skull cavity by running a micro spatula underneath and along the length of the brain from the olfactory lobes to the beginning of the spinal cord. After gently transferring the brain to a $60 \mathrm{~mm}$ petri dish, the tissues were rinsed with phosphate buffer saline (PBS) to remove any red blood cells and clots.

The brain were then transferred to a second petri dish and cut into small pieces in ice chilled 10\% PBS solution, slices were sonicated for $45 \mathrm{~min}$ in 100 cycles [29]. The extracts were separated from cells debris by centrifugation at 1500rpm using bench top centrifuge for 5 minutes, and then the supernatant was collected and used for the assay.

\section{Biochemical Analyses}

\section{Estimation of Catalase (CAT) Activity}

The commercial Cayman’s Catalase Assay Kit was obtained from Cayman ${ }^{\circledR}$ Chemical Company, Ann Arbor, USA and was used to estimate activities of serum catalase according to the manufacturer's instructions following the method of Johansson and Borg [30]. Three wells were designated as sample, standard and control. To each well, $100 \mu$ l of assay buffer and $30 \mu \mathrm{l}$ of methanol were added. To standard well, $20 \mu \mathrm{l}$ of prepared standard (Formaldehyde Standards) were added and to sample well $20 \mu \mathrm{l}$ of serum were added. $20 \mu \mathrm{l}$ of $\mathrm{H}_{2} \mathrm{O}_{2}$ were added to each well to initiate the reaction. The plate was covered with lid and incubated on a shaker for 20 minutes at room temperature. To each well, $30 \mu \mathrm{l}$ of potassium hydroxide were added to terminate the reaction and $30 \mu \mathrm{l}$ of purpald were then added. The plate was covered once again and incubated for 10 minutes at room temperature on a shaker. Once again, to each well, $10 \mu \mathrm{l}$ of potassium periodate were added, covered and incubated for 5 minutes on a shaker. The absorbance was read at 540nm using Rayto RT 2100C plate reader produced by Shanghai International Holding Corporate, Humberg, Germany.

\section{Estimation of Superoxide Dismutase (SOD) Activity}

Cayman’s Superoxide Dismutase Assay Kit from Cayman ${ }^{\circledR}$ Chemical Company, Ann Arbor, USA was used according to the manufacturer's instructions to quantify the serum activities of superoxide dismutase. Two wells were designated as standard and sample. To each well $200 \mu \mathrm{l}$ of the diluted radical detector, $10 \mu \mathrm{l}$ each of prepared standard to the serum were added to the standard 
well and sample well respectively. Twenty microliter $(20 \mu \mathrm{l})$ of diluted xanthine oxidase was added to both standard and sample wells to initiate the reaction. The plate was shaken for a few seconds and covered with cover plate. The plate was then incubated on a shaker at room temperature for 20 minutes and absorbance was read at $450 \mathrm{~nm}$ using Rayto RT 2100C plate reader produced by Shanghai International Holding Corporate, Humberg, Germany with the method described by Marklund [31].

\section{Estimation of Glutathione peroxidase (GPx) Activity}

The commercial assay kits of Cayman obtained from Cayman ${ }^{\circ}$ chemical company, Ann Arbor, USA was used to carry out the analysis of GPx in accordance with the manufacture's guide. In brief, three wells were designated as sample, non-enzymatic and positive control. To sample well, $100 \mu \mathrm{l}$ of assay buffer, $50 \mu \mathrm{l}$ of co-substrate mixture and $20 \mu \mathrm{l}$ of serum were added. To non-enzymatic well, $120 \mu \mathrm{l}$ of assay buffer and $50 \mu \mathrm{l}$ of co-substrate mixture were added and to positive control well $100 \mu \mathrm{l}$ of assay buffer, $50 \mu \mathrm{l}$ of cosubstrate mixture and $20 \mu \mathrm{l}$ of diluted GPx were added. The reaction was initiated by adding $20 \mu \mathrm{l}$ of cumenehydroperoxide to each well and the plate was carefully shaken for a few seconds. The absorbance was read at $340 \mathrm{~nm}$ using Rayto RT $2100 \mathrm{C}$ plate reader produced by Shanghai International Holding Corporate, Humberg, Germany, once every 3 minutes according to the method described by [32].

$$
\begin{aligned}
& \Delta \mathrm{Abs} / \mathrm{min}=\frac{\text { Abs }(\text { time } 2)-\text { Abs }(\text { time } 1)}{\text { Time } 2(\min )-\operatorname{Time} 1(\min )} \\
& \text { GPx activity }=\frac{A b s / \mathrm{min}}{0.00373 \mu / \mathrm{M}} \times \frac{0.19 \mathrm{ml}}{0.02 \mathrm{ml}}=\mathrm{nmol} / \mathrm{mn} / \mathrm{ml}
\end{aligned}
$$

\section{Estimation of Lipid Peroxidation (MDA) Concentration}

Estimation of lipid peroxidation was performed using Cayman's assay kits obtained from Cayman ${ }^{\circ}$ Chemical Company, Ann Arbor, USA, following the manufacture's instruction. Into a test tube, $0.1 \mathrm{ml}$ of serum was added and treated with $2 \mathrm{ml}$ of TBA-TCA-HCl ( $1: 1: 1$ ratio) reagent (Thiobarbituric acid $0.37 \%, 0.25 \mathrm{~N} \mathrm{HCl}$ and $15 \% \mathrm{TCA})$. The tube was placed in water-bath for 15 minutes, cooled and centrifuged at room temperature for 10 minutse at $1000 \mathrm{rpm}$. The absorbance of clear supernatant was measured against reference blank at $535 \mathrm{~nm}$ using Rayto RT 2100C plate reader produced by Shanghai International Holding Corporate, Humberg, Germany. The concentration of TBARS was calculated using the molar extinction coefficient of malondialdehyde (1.5 $\mathrm{x} 10^{5} \mathrm{~mol} / \mathrm{l} / \mathrm{cm}$ ) following the method highlighted by Niehans and Samuelson [33].

\section{Data Analysis}

Statistical programme for Social Sciences (SPSS22.0) was used to analyze the data. Results were expressed as means \pm SD. All Data were analyzed by one-way analysis of variance (ANOVA); Turkey Alpha Post-hoc Test was used for multiple comparisons between groups and concentrations.

\section{Results}

\section{Beam Walking Test (BWT)}

Figure 1 shows the results of the beam walking test performed to assess motor function of the experimental rats after stroke induction (SI). The scores indicated that rats in the treated groups improved on their first BWT score from 0-1 to 3-5 while the SINT group rats did not show improvement from their first score.

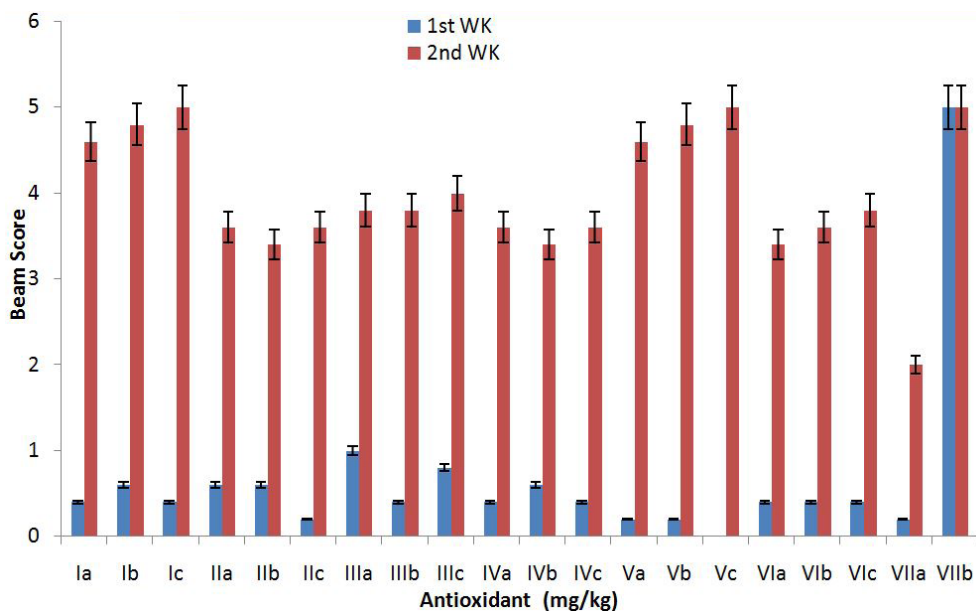

Ia- VC- Vitamin C 22.5mg/kg, Ib- VC- Vitamin C 45mg/kg, Ic-VC- Vitamin C 67.5mg/kg, IIa-VE-Vitamin E 22.5mg/kg, IIb- VE-Vitamin E $45 \mathrm{mg} / \mathrm{kg}$, IIc-VE-Vitamin E 67.5mg/kg, IIIa- UA-Uric Acid 22.5mg/kg, IIIb- UA-Uric Acid 45mg/kg, IIIc- UA-Uric Acid 67.5mg/kg, IVa- ALAAlpha Lipoic Acid 22.5mg/kg, IVb- ALA-Alpha Lipoic Acid 45mg/kg, IVc- ALA-Alpha Lipoic Acid 67.5mg/kg, Va- DMSO- Dimethyl sulfoxide $22.5 \mathrm{mg} / \mathrm{kg}$, Vb-DMSO- Dimethyl sulfoxide 45mg/kg, Vc-DMSO- Dimethyl sulfoxide 67.5mg/kg, VIa- Mann- Mannitol 22.5mg/kg, VIb- MannMannitol 45mg/kg, VIc- Mann- Mannitol $67.5 \mathrm{mg} / \mathrm{kg}$, VIIa- SINT- Stroke induced non-treated, VIIb- NSINT- Non stroke induced non-treated Figure 1:The effect of antioxidant supplementation on Motor function of IS rats using BWT 


\section{Staircase Test (SCT)}

Figure 2 shows the results of staircase climbing test performed to assess motor function of the experimental rats after SI. The scores indicated that rats from treated groups improved on their first score from 0-1-1.2 to 3-5 while the SINT group rats did not show much improvement from their first score.

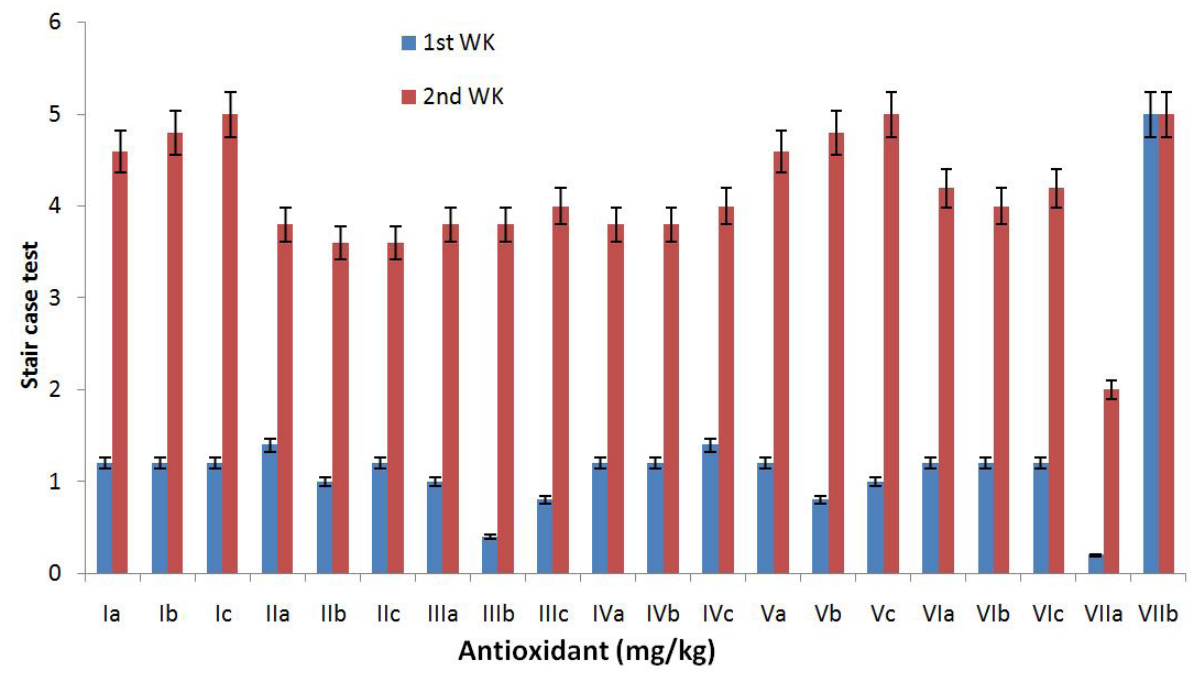

Ia- VC- Vitamin C $22.5 \mathrm{mg} / \mathrm{kg}$, Ib- VC- Vitamin C $45 \mathrm{mg} / \mathrm{kg}$, Ic-VC- Vitamin C $67.5 \mathrm{mg} / \mathrm{kg}$, IIa-VE-Vitamin E $22.5 \mathrm{mg} / \mathrm{kg}$, IIb- VE-Vitamin E 45mg/kg, IIc-VE-Vitamin E $67.5 \mathrm{mg} / \mathrm{kg}$, IIIa- UA-Uric Acid $22.5 \mathrm{mg} / \mathrm{kg}$, IIIb- UA-Uric Acid 45mg $/ \mathrm{kg}$, IIIcUA-Uric Acid 67.5mg/kg, IVa- ALA-Alpha Lipoic Acid $22.5 \mathrm{mg} / \mathrm{kg}$, IVb- ALA-Alpha Lipoic Acid $45 \mathrm{mg} / \mathrm{kg}$, IVc- ALA-Alpha Lipoic Acid $67.5 \mathrm{mg} / \mathrm{kg}$, Va- DMSO- Dimethyl sulfoxide $22.5 \mathrm{mg} / \mathrm{kg}$, Vb-DMSO- Dimethyl sulfoxide $45 \mathrm{mg} / \mathrm{kg}$, Vc-DMSODimethyl sulfoxide $67.5 \mathrm{mg} / \mathrm{kg}$, VIa- Mann- Mannitol 22.5mg/kg, VIb- Mann- Mannitol 45mg/kg, VIc- Mann- Mannitol $67.5 \mathrm{mg} / \mathrm{kg}$, VIIa- SINT- Stroke induced non-treated, VIIb- NSINT- Non stroke induced non-treated

Figure 2: The effect of antioxidant supplementation on Motor function of IS rats using SCT

\section{Cylinder Test (CT)}

Figure 3 shows the result of cylinder test performed to assess motor function of the experimental rats after SI. The scores indicated that rats from treated groups improved on their first score from 0-1 to 3-5 while the SINT group rats did not show much improvement from their first score. The SNINT group showed the same results for the two tests.

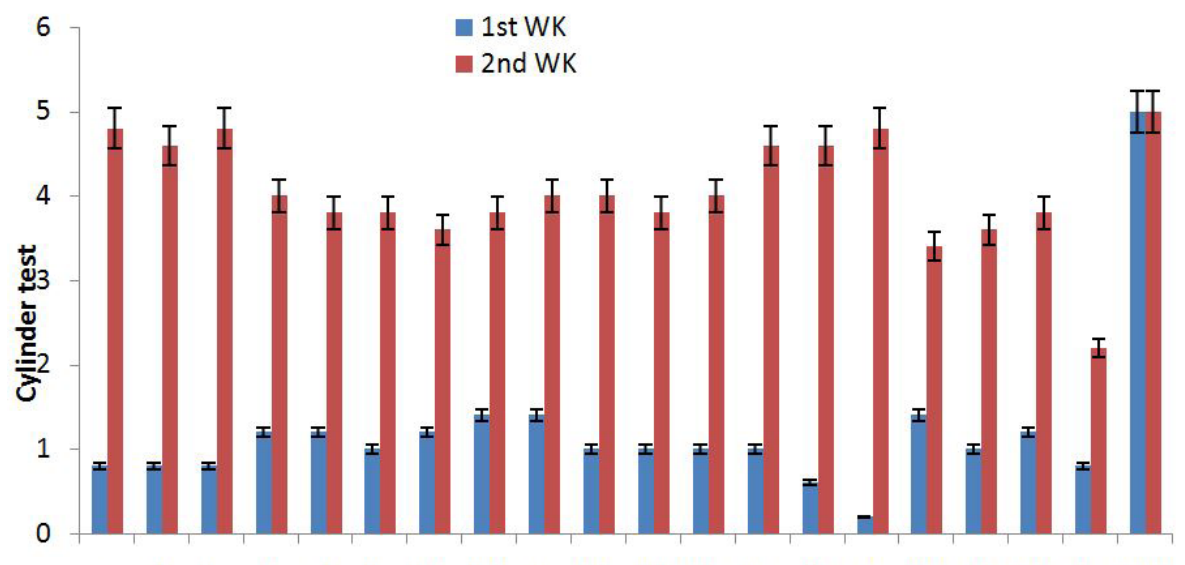

la Ib Ic Ila Ilb Ilc IIla IIIb IIlc IVa IVb IVc Va Vb Vc Vla VIb Vlc VIla VIIb

Antioxidant $(\mathrm{mg} / \mathrm{kg})$

Ia- VC- Vitamin C $22.5 \mathrm{mg} / \mathrm{kg}$, Ib- VC- Vitamin C $45 \mathrm{mg} / \mathrm{kg}$, Ic-VC- Vitamin C $67.5 \mathrm{mg} / \mathrm{kg}$, IIa-VE-Vitamin E $22.5 \mathrm{mg} / \mathrm{kg}$, IIb- VE-Vitamin E $45 \mathrm{mg} / \mathrm{kg}$, IIc-VE-Vitamin E $67.5 \mathrm{mg} / \mathrm{kg}$, IIIa- UA-Uric Acid $22.5 \mathrm{mg} / \mathrm{kg}$, IIIb- UA-Uric Acid 45mg $/ \mathrm{kg}$, IIIcUA-Uric Acid 67.5mg/kg, IVa- ALA-Alpha Lipoic Acid $22.5 \mathrm{mg} / \mathrm{kg}$, IVb- ALA-Alpha Lipoic Acid $45 \mathrm{mg} / \mathrm{kg}$, IVc- ALA-Alpha Lipoic Acid $67.5 \mathrm{mg} / \mathrm{kg}$, Va- DMSO- Dimethyl sulfoxide $22.5 \mathrm{mg} / \mathrm{kg}$, Vb-DMSO- Dimethyl sulfoxide $45 \mathrm{mg} / \mathrm{kg}$, Vc-DMSODimethyl sulfoxide $67.5 \mathrm{mg} / \mathrm{kg}$, VIa- Mann- Mannitol 22.5mg/kg, VIb- Mann- Mannitol 45mg/kg, VIc- Mann- Mannitol $67.5 \mathrm{mg} / \mathrm{kg}$, VIIa- SINT- Stroke induced non-treated, VIIb- NSINT- Non stroke induced non-treated

Figure 3: The effect of antioxidant supplementation on Motor function of IS rats using CT

\section{Modified Neurological Severity Score (mnss)}

Figure 4 shows the outcome of the neurological assessment (modified neurological severity score) of all the experimental groups. The NSINT group of rats showed no neurological changes. There were considerable improvements in the neurological response in the rats treated with the antioxidants as indicated by their scores. The SINT group did not show significant improvement in their neurological score. 


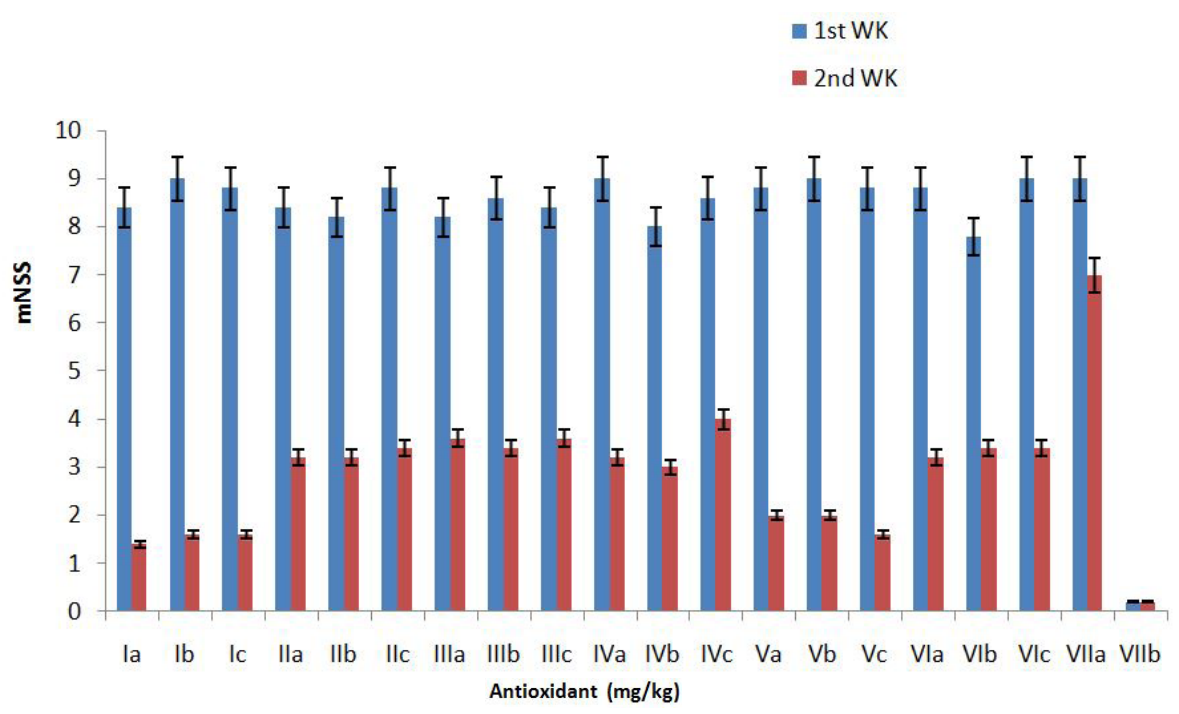

Ia- VC- Vitamin C 22.5mg/kg, Ib- VC- Vitamin C 45mg/kg, Ic-VC-Vitamin C 67.5mg/kg, IIa-VE-Vitamin E 22.5mg/kg, IIb- VE-Vitamin E $45 \mathrm{mg} / \mathrm{kg}$, IIc-VE-Vitamin E $67.5 \mathrm{mg} / \mathrm{kg}$, IIIa- UA-Uric Acid $22.5 \mathrm{mg} / \mathrm{kg}$, IIIb- UA-Uric Acid $45 \mathrm{mg} / \mathrm{kg}$, IIIc- UA-Uric Acid 67.5mg/kg, IVa- ALA-Alpha Lipoic Acid $22.5 \mathrm{mg} / \mathrm{kg}$, IVb- ALA-Alpha Lipoic Acid 45mg/kg, IVc- ALA-Alpha Lipoic Acid 67.5mg/kg, Va- DMSO- Dimethyl sulfoxide 22.5mg/kg, Vb-DMSODimethyl sulfoxide 45mg/kg, Vc-DMSO- Dimethyl sulfoxide 67.5mg $/ \mathrm{kg}$, VIa- Mann- Mannitol 22.5mg/kg, VIb- Mann- Mannitol 45mg/kg, VIc- MannMannitol $67.5 \mathrm{mg} / \mathrm{kg}$, VIIa- SINT- Stroke induced non-treated, VIIb- NSINT- Non stroke induced non-treated

Figure 4: The effect of antioxidant supplementation on Motor function of IS rats using mNSS

\section{Oxidative Stress Analyses}

Effect of Supplementation with LMWA on Serum and Brain Tissue Homogenates (BTH) SOD Activity of SI Rats: The effect of LMWA on the activity SOD on ischemic stroke of albino rats is presented in Table 1. The results indicated that SI caused significant $(\mathrm{P}<0.05)$ decrease in the activity of the enzyme SOD. Treatment with LMWA at $22.5 \mathrm{mg} / \mathrm{kg}, 45 \mathrm{mg} / \mathrm{kg}$ and $67.5 \mathrm{mg} / \mathrm{kg}$ body weight (BW) resulted in significant $(\mathrm{P}<0.05)$ increase of SOD activity across the groups when compared with the SOD activity of rats in

\begin{tabular}{|c|c|c|c|c|c|c|c|c|}
\hline \multicolumn{5}{|c|}{ Serum SOD Activities } & \multicolumn{4}{|c|}{ BTH SOD Activities } \\
\hline Groups & $0 \mathrm{mg} / \mathrm{kg}$ & $22.5 \mathrm{mg} / \mathrm{kg}$ & $45 \mathrm{mg} / \mathrm{kg}$ & $67.5 \mathrm{mg} / \mathrm{kg}$ & $0 \mathrm{mg} / \mathrm{kg}$ & $22.5 \mathrm{mg} / \mathrm{kg}$ & $45 \mathrm{mg} / \mathrm{kg}$ & $67.5 \mathrm{mg} / \mathrm{kg}$ \\
\hline VC & & $48.58 \pm 3.28^{\mathrm{a}, \mathrm{x}}$ & $74.53 \pm 2.59^{\mathrm{a}, \mathrm{z}}$ & $74.53 \pm 2.59^{\mathrm{a}, \mathrm{z}}$ & & $71.90 \pm 3.71^{\mathrm{ac}, \mathrm{x}}$ & $93.09 \pm 3.87^{\mathrm{a}, \mathrm{y}}$ & $104.48 \pm 6.38^{\mathrm{a}, \mathrm{z}}$ \\
\hline VE & & $32.80 \pm 2.29^{\mathrm{b}, \mathrm{x}}$ & $45.33 \pm 1.00^{\mathrm{b}, y}$ & $45.33 \pm 1.00^{\mathrm{b}, y}$ & & $75.99 \pm 7.96^{\mathrm{ab}, \mathrm{x}}$ & $86.41 \pm 3.36^{\text {a,y }}$ & $89.05 \pm 4.67^{\mathrm{b}, \mathrm{y}}$ \\
\hline UA & & $20.43 \pm 2.31^{\mathrm{cd}, \mathrm{x}}$ & $31.35 \pm 0.50^{\mathrm{cd}, y}$ & $31.35 \pm 0.50^{\mathrm{cd}, y}$ & & $65.66 \pm 4.89^{\mathrm{ac}, \mathrm{x}}$ & $74.53 \pm 2.59 \mathrm{~b}^{c, y}$ & $75.71 \pm 5.41^{\mathrm{cf,y}}$ \\
\hline ALA & & $24.59 \pm 1.24^{\mathrm{df}, \mathrm{x}}$ & $29.62 \pm 0.94^{\mathrm{df}, z}$ & $29.62 \pm 0.94^{\mathrm{df}, z}$ & & $83.96 \pm 2.74^{\mathrm{b}, \mathrm{x}}$ & $97.58 \pm 3.69^{\mathrm{a}, y}$ & $131.34 \pm 7.83^{\mathrm{d}, \mathrm{z}}$ \\
\hline DMSO & & $65.66 \pm 4.89^{e, x}$ & $100.88 \pm 4.52^{\mathrm{ey} y}$ & $100.88 \pm 4.52^{e, y}$ & & $73.69 \pm 3.77^{\mathrm{ab}, \mathrm{x}}$ & $84.11 \pm 4.86^{\mathrm{ab}, y}$ & $131.34 \pm 7.83^{\mathrm{de}, 2}$ \\
\hline Man & & $19.06 \pm 0.49^{\mathrm{cf}, x}$ & $27.49 \pm 1.48^{\mathrm{cf}, z}$ & $27.49 \pm 1.48^{\mathrm{cf}, z}$ & & $61.96 \pm 1.51^{c, x}$ & $65.49 \pm 3.01^{c, x}$ & $70.95 \pm 2.30^{\mathrm{fy}}$ \\
\hline SINT & $5.84 \pm 1.60^{\mathrm{g}, \mathrm{x}}$ & & & & $42.60 \pm 1.37^{\mathrm{d}, x}$ & & & \\
\hline NSINT & $108.38 \pm 8.14^{\mathrm{h}, \mathrm{x}}$ & & & & $150.65 \pm 9.79^{e, x}$ & & & \\
\hline
\end{tabular}

Means with different superscript letters are significantly different $(\mathrm{P}<0.05)$ across the rows and down the columns;

VC: Vitamin C; VE: Vitamin E; UA: Uric acid; ALA: Alpha lipoic acid; DMSO: Dimethyl sulfoxide Man Mannitol SINT: Stroke induced non-treated; NSINT: Non stroke induced non-treated: SOD: Superoxide dismutase, BTH: Brain tissue homogenates

Table 1: Effect of Antioxidants supplementation on Serum and BTH on SOD Activities of experimental rats

\begin{tabular}{|c|c|c|c|c|c|c|c|c|}
\hline \multicolumn{5}{|c|}{ Serum CAT Activities } & \multicolumn{4}{|c|}{ BTH CAT Activities } \\
\hline Groups & $0 \mathrm{mg} / \mathrm{kg}$ & $22.5 \mathrm{mg} / \mathrm{kg}$ & $45 \mathrm{mg} / \mathrm{kg}$ & $67.5 \mathrm{mg} / \mathrm{kg}$ & $0 \mathrm{mg} / \mathrm{kg}$ & $22.5 \mathrm{mg} / \mathrm{kg}$ & 45 mg/kg & $67.5 \mathrm{mg} / \mathrm{kg}$ \\
\hline VC & & $33.96 \pm 1.33^{\mathrm{a}, \mathrm{x}}$ & $46.42 \pm 0.99^{\mathrm{a}, \mathrm{y}}$ & $62.69 \pm 0.55^{\mathrm{a}, 2}$ & & $67.50 \pm 0.39^{\mathrm{a}, \mathrm{x}}$ & $80.25 \pm 6.00^{\mathrm{a}, y}$ & $90.59 \pm 0.87^{\mathrm{a}, \mathrm{z}}$ \\
\hline VE & & $23.59 \pm 2.58^{\text {be, }}$ & $33.65 \pm 1.85^{\mathrm{b}, \mathrm{y}}$ & $41.01 \pm 1.23^{\mathrm{b}, z}$ & & $58.58 \pm 0.59^{\mathrm{b}, \mathrm{x}}$ & $69.49 \pm 0.59^{\text {be,y }}$ & $70.05 \pm 0.00^{\mathrm{b}, \mathrm{y}}$ \\
\hline UA & & $15.51 \pm 1.00^{c, x}$ & $24.17 \pm 1.05^{\mathrm{cd}, \mathrm{y}}$ & $45.42 \pm 1.05^{\mathrm{bc}, z}$ & & $55.46 \pm 0.39^{c, x}$ & $58.58 \pm 0.59^{\mathrm{c}, y}$ & $61.41 \pm 0.59^{c, z}$ \\
\hline ALA & & $24.29 \pm 1.47^{\mathrm{cd}, \mathrm{x}}$ & $30.54 \pm 0.55^{\text {bd,y }}$ & $48.28 \pm 0.86^{\mathrm{d}, y}$ & & $69.77 \pm 0.39^{\mathrm{d}, \mathrm{x}}$ & $86.20 \pm 1.27^{\mathrm{d}, y}$ & $94.42 \pm 0.39^{\mathrm{d}, z}$ \\
\hline DMSO & & $34.92 \pm 0.81^{\mathrm{a}, \mathrm{x}}$ & $48.25 \pm 0.59^{\mathrm{a}, \mathrm{y}}$ & $70.49 \pm 0.33^{\mathrm{de}, z}$ & & $64.67 \pm 0.81^{e, x}$ & $69.49 \pm 0.59^{\mathrm{e}, y}$ & $86.20 \pm 1.27^{\mathrm{e}, \mathrm{z}}$ \\
\hline Man & & $17.64 \pm 1.12^{\text {ce, } x}$ & $21.60 \pm 1.71^{c e, y}$ & $26.56 \pm 1.85^{\mathrm{f}, z}$ & & $53.19 \pm 0.92^{\mathrm{f}, \mathrm{x}}$ & $55.60 \pm 0.39^{\mathrm{cf}, \mathrm{y}}$ & $58.72 \pm 0.00^{f, z}$ \\
\hline SINT & $0.89 \pm 0.14^{\mathrm{f}, \mathrm{x}}$ & & & & $38.04 \pm 1.36^{g, x}$ & & & \\
\hline NSINT & $69.91 \pm 8.87^{g, x}$ & & & & $104.90 \pm 0.59^{\mathrm{h}, \mathrm{x}}$ & & & \\
\hline
\end{tabular}

Means with different superscript letters are significantly different $(\mathrm{P}<0.05)$ across the rows and down the columns;

VC: Vitamin C; VE: Vitamin E; UA: Uric acid; ALA: Alpha lipoic acid; DMSO: Dimethyl sulfoxide Man Mannitol SINT: Stroke induced non-treated; NSINT: Non stroke induced non-treated: SOD: Superoxide dismutase, BTH: Brain tissue homogenates

Table 2: Effect of Antioxidants supplementation on Serum and BTH on CAT Activities of experimental rats 
SINT group in a concentration dependent manner. The effect on brain tissue homogenates SOD activities on the supplementation of antioxidants on ischemic stroke in wistar rats is presented in Table 2. The results indicated that SI caused significant $(\mathrm{P}<0.05)$ decrease in the activity of the enzyme SOD in SINT group. After supplementation of the antioxidants, SOD activity increased significantly $(\mathrm{P}<0.005)$ across the groups when compared with the SOD activity of rats in SINT group.

Effect of Supplementation with LMWA on Serum and Brain Tissue Homogenates (BTH) CAT Activity of SI Rats: Antioxidants supplementations effect on the serum activity of catalase is presented in Table 2. The results indicated that SI caused significant $(\mathrm{P}<0.05)$ decrease in the activity of the enzyme as shown by SINT group of the experimental rats. After the supplementation, the lowered catalase enzyme activity seen in SINT group was reverted in various antioxidants treatment groups when compared with the NSNT group. The effect of brain homogenates of CAT activity on the supplementation of antioxidants on ischemic stroke in wistar rats is presented in Table 2. The results indicated that SI caused significant $(\mathrm{P}<0.05)$ decrease in the activity of the enzyme CAT in SINT group. After supplementation of the antioxidants in all the groups, CAT activity increased significantly $(\mathrm{P}<0.05)$ across the groups when compared with the CAT of rats in SINT group.

Effect of Supplementation of LMWA on Serum and Brain Tissue Homogenates (BTH) GPx Activity of SI Rats: The effect of antioxidants supplementations on the serum activity of GPx is presented in Table 3. The results indicated that SI caused significant $(\mathrm{P}<0.05)$ decrease in the activity of GPx as shown by SINT group of the experimental rats. The effect of antioxidants supplementations on the brain tissue homogenates activity of GPx is presented in Table 3. The results indicated that SI caused significant $(\mathrm{P}<0.05)$ decrease in the activity of GPx as revealed by SINT group of the experimental rats. Following the supplementations, the GPx enzyme activity significantly $(\mathrm{P}<0.05)$ increased in various antioxidants treatment groups when compared with the NSNT and SINT groups.

\begin{tabular}{|c|c|c|c|c|c|c|c|c|}
\hline \multicolumn{5}{|c|}{ Serum GPx Activities } & \multicolumn{4}{|c|}{ BTH GPx Activities } \\
\hline Groups & $0 \mathrm{mg} / \mathrm{kg}$ & $22.5 \mathrm{mg} / \mathrm{kg}$ & $45 \mathrm{mg} / \mathrm{kg}$ & $67.5 \mathrm{mg} / \mathrm{kg}$ & $0 \mathrm{mg} / \mathrm{kg}$ & $22.5 \mathrm{mg} / \mathrm{kg}$ & $45 \mathrm{mg} / \mathrm{kg}$ & $67.5 \mathrm{mg} / \mathrm{kg}$ \\
\hline VC & & $47.32 \pm 4.36^{\mathrm{a}, \mathrm{x}}$ & $72.28 \pm 9.71^{\text {a,y }}$ & $94.18 \pm 1.80^{\mathrm{a}, \mathrm{z}}$ & & $87.10 \pm 7.93^{\mathrm{a}, \mathrm{x}}$ & $117.67 \pm 1.14^{\mathrm{a}, \mathrm{y}}$ & $121.23 \pm 2.90^{a, z}$ \\
\hline VE & & $31.07 \pm 2.79^{\mathrm{bd}, x}$ & $53.49 \pm 4.41^{\mathrm{bd}, y}$ & $57.56 \pm 2.99^{\text {bdf,y }}$ & & $53.49 \pm 4.41^{\mathrm{b}, \mathrm{x}}$ & $72.28 \pm 9.71^{\mathrm{b}, y}$ & $83.03 \pm 2.90^{\mathrm{b}, \mathrm{y}}$ \\
\hline UA & & $26.49 \pm 1.39^{\mathrm{bcf}, \mathrm{x}}$ & $35.66 \pm 3.12^{\mathrm{cf}, y}$ & $57.56 \pm 7.34^{\mathrm{bc}, z}$ & & $35.66 \pm 3.12^{c, x}$ & $53.49 \pm 4.41^{c e, y}$ & $58.58 \pm 9.00^{c, z}$ \\
\hline ALA & & $25.47 \pm 0.00^{c \mathrm{~cd}, \mathrm{x}}$ & $45.84 \pm 12.99^{\mathrm{cd}, \mathrm{y}}$ & $66.73 \pm 2.13^{\text {cd, }, z}$ & & $90.67 \pm 4.63^{\mathrm{a}, \mathrm{x}}$ & $116.65 \pm 2.13^{a, y}$ & $139.57 \pm 4.89^{\mathrm{d}, \mathrm{z}}$ \\
\hline DMSO & & $75.89 \pm 1.14^{e, x}$ & $89.14 \pm 5.97^{\text {e,y }}$ & $106.46 \pm 2.13^{\mathrm{e}, \mathrm{z}}$ & & $89.14 \pm 5.97^{\mathrm{ad}, \mathrm{x}}$ & $96.78 \pm 3.12^{\mathrm{d}, y}$ & $111.55 \pm 1.14^{\mathrm{d}, \mathrm{z}}$ \\
\hline Man & & $19.36 \pm 7.11^{\mathrm{df}, \mathrm{x}}$ & $38.20 \pm 1.39^{\text {ef,y }}$ & $62.14 \pm 6.13^{\mathrm{cdf}, z}$ & & $47.37 \pm 6.64^{\mathrm{bd}, \mathrm{x}}$ & $50.43 \pm 4.89^{e, x}$ & $49.92 \pm 7.77^{\mathrm{cf}, x}$ \\
\hline SINT & $3.57 \pm 1.39^{f, x}$ & & & & $30.05 \pm 2.13^{c e, x}$ & & & \\
\hline NSINT & $113.59 \pm 7.77^{\mathrm{g}, \mathrm{x}}$ & & & & $158.41 \pm 7.07^{\mathrm{f}, \mathrm{x}}$ & & & \\
\hline
\end{tabular}

Means with different superscript letters are significantly different $(\mathrm{P}<0.05)$ across the rows and down the columns;

VC: Vitamin C; VE: Vitamin E; UA: Uric acid; ALA: Alpha lipoic acid; DMSO: Dimethyl sulfoxide Man Mannitol SINT: Stroke induced non-treated; NSINT: Non stroke induced non-treated: SOD: Superoxide dismutase, BTH: Brain tissue homogenates

Table 3: Effect of Antioxidants supplementation on Serum and BTH on GPx Activities of experimental rats

Effect of Supplementation of LMWA on the Serum and Brain Tissue Homogenates (BTH) MDA Concentration of SI Rats: The effect of antioxidant supplementations on the serum MDA concentration is presented in Table 4 . The results indicated that SI caused significant $(\mathrm{P}<0.05)$ increase in the concentration of MDA in the SINT group. After being given various antioxidants at $22.5 \mathrm{mg} / \mathrm{kg}, 45 \mathrm{mg} / \mathrm{kg}$ and $67.5 \mathrm{mg} / \mathrm{kg}$ BW, the concentration of the MDA significantly $(\mathrm{P}<0.05)$ decrease in all supplemented groups in a concentration dependent manner. The effect of antioxidant supplementations on the brain tissue homogenate of MDA concentration is presented in Table 4 . The results indicated that SI caused significant $(\mathrm{P}<0.05)$ increase in the concentration of MDA in the SINT group. After given various antioxidants at $22.5 \mathrm{mg} / \mathrm{kg}, 45 \mathrm{mg} / \mathrm{kg}$ and $67.5 \mathrm{mg} / \mathrm{kg}$ BW to the experimental rats, the concentration of MDA significantly $(\mathrm{P}<0.05)$ decrease in a concentration dependent manner across the treated groups.

\begin{tabular}{|c|c|c|c|c|c|c|c|c|}
\hline \multicolumn{5}{|c|}{ Serum MDA Concentrations } & \multicolumn{4}{|c|}{ BTH MDA Concentration } \\
\hline Groups & $0 \mathrm{mg} / \mathrm{kg}$ & $22.5 \mathrm{mg} / \mathrm{kg}$ & $45 \mathrm{mg} / \mathrm{kg}$ & $67.5 \mathrm{mg} / \mathrm{kg}$ & $0 \mathrm{mg} / \mathrm{kg}$ & $22.5 \mathrm{mg} / \mathrm{kg}$ & $45 \mathrm{mg} / \mathrm{kg}$ & $67.5 \mathrm{mg} / \mathrm{kg}$ \\
\hline vC & & $0.67 \pm 0.36^{\mathrm{a}, \mathrm{x}}$ & $0.53 \pm 0.01^{\mathrm{a}, \mathrm{y}}$ & $0.31 \pm 0.02^{\mathrm{a}, \mathrm{z}}$ & & $0.95 \pm 0.13^{\mathrm{a}, \mathrm{x}}$ & $1.00 \pm 0.00^{\mathrm{a}, \mathrm{y}}$ & $0.87 \pm 0.00^{\mathrm{a}, \mathrm{z}}$ \\
\hline VE & & $0.89 \pm 0.43^{a, x}$ & $0.73 \pm 0.04^{\mathrm{b}, y}$ & $0.53 \pm 0.02^{\mathrm{b}, \mathrm{z}}$ & & $1.14 \pm 0.18^{\mathrm{ac}, \mathrm{x}}$ & $1.12 \pm 0.02^{\mathrm{b}, \mathrm{x}}$ & $1.08 \pm 0.00^{\mathrm{bc}, \mathrm{X}}$ \\
\hline UA & & $1.67 \pm 0.17^{\mathrm{b}, \mathrm{x}}$ & $0.84 \pm 0.02^{\mathrm{cf}, y}$ & $0.75 \pm 0.11^{c, z}$ & & $1.67 \pm 0.17^{\mathrm{b}, \mathrm{x}}$ & $1.04 \pm 0.024^{\mathrm{ab}, \mathrm{y}}$ & $0.99 \pm 0.00^{c, y}$ \\
\hline ALA & & $1.28 \pm 0.14^{c, x}$ & $0.74 \pm 0.08^{\mathrm{bd}, \mathrm{y}}$ & $0.65 \pm 0.01^{\mathrm{d}, \mathrm{y}}$ & & $1.15 \pm 0.08^{\mathrm{ac}, \mathrm{x}}$ & $0.97 \pm 0.00^{\mathrm{a}, \mathrm{y}}$ & $0.87 \pm 0.00^{\mathrm{d}, \mathrm{z}}$ \\
\hline DMSO & & $0.60 \pm 0.31^{\mathrm{a}, \mathrm{x}}$ & $0.24 \pm 0.05^{e, y}$ & $0.19 \pm 0.15^{\mathrm{eh}, \mathrm{y}}$ & & $1.28 \pm 0.14^{\mathrm{c}, \mathrm{x}}$ & $1.00 \pm 0.00^{\mathrm{a}, \mathrm{y}}$ & $0.79 \pm 0.01^{\mathrm{ad}, \mathrm{z}}$ \\
\hline Man & & $2.05 \pm 0.31^{\mathrm{d}, \mathrm{x}}$ & $0.85 \pm 0.04^{\mathrm{fy}}$ & $0.85 \pm 0.00^{f, y}$ & & $2.77 \pm 0.12^{\mathrm{d}, \mathrm{x}}$ & $1.85 \pm 0.04^{c, y}$ & $1.78 \pm 0.01^{\mathrm{e}, \mathrm{y}}$ \\
\hline SINT & $2.75 \pm 0.08^{e, x}$ & & & & $4.77 \pm 0.10^{e, x}$ & & & \\
\hline NSINT & $0.13 \pm 0.05^{\mathrm{f}, \mathrm{x}}$ & & & & $0.77 \pm 0.07^{\mathrm{a}, \mathrm{x}}$ & & & \\
\hline
\end{tabular}

Means with different superscript letters are significantly different $(\mathrm{P}<0.05)$ across the rows and down the columns; VC: Vitamin C; VE: Vitamin E; UA: Uric acid; ALA: Alpha lipoic acid; DMSO: Dimethyl sulfoxide Man Mannitol SINT: Stroke induced non-treated; NSINT: Non stroke induced non-treated: SOD: Superoxide dismutase, BTH: Brain tissue homogenates

Table 4: Effect of Antioxidants supplementation on Serum and BTH on MDA Concentrations of experimental rats 


\section{Discussion}

A significant $(\mathrm{P}<0.05)$ decrease in the antioxidant enzymes (SOD, CAT, GPX) activities and a significant $(\mathrm{P}<0.05)$ increase in the concentration of MDA (Table 1-4) was observed in IS induced rats. This could be as a result of an increase in the production of reactive oxygen species (ROS) and free radicals produced after induction of the ischemic stroke, leading to the depletion of the enzymatic antioxidants such as SOD, CAT, GPX, thus leading to oxidative stress (OS) which is a major player in the pathophysiology of neurodegenerative diseases such as ischemic stroke, traumatic brain injury etc. This is in line with the report of Gilgun-Sherki et al. [34], it was stated in there study that free radicals can cause destruction to important cellular macromolecules such as carbohydrates, lipids, proteins and nucleic acids leading to consequent cell death by modes of apoptosis or necrosis.

A significant $(\mathrm{P}<0.05)$ increase in the activities of antioxidant enzymes was observed following treatment with LMWA at $22.5 \mathrm{mg} / \mathrm{kg}$, $45 \mathrm{mg} / \mathrm{kg}$ and $67.5 \mathrm{mg} / \mathrm{kg}$ body weight (BW) for all the groups supplemented, Antioxidant enzyme activities increased significantly $(\mathrm{P}<0.05)$ across the groups and OS biomarkers MDA concentration significantly $(\mathrm{P}<0.05)$ decreased when compared with the antioxidants enzyme activities and MDA concentration of rats in SINT group in a concentration dependent manner. The increase in the activities of antioxidants enzyme activities seen in vitamin $\mathrm{C}$ is ascribed to the report by some researchers [35], where they reported that vitamin $\mathrm{C}$ is an important antioxidant that has capacity to limit oxidative lipid damage in biological systems. In addition, it is also found to be a potent water affinity scavenger in biological fluids and tissues [35]. Vitamin C is a strong reducing agent and by donating electron(s), thus it neutralizes ROS directly, which always causes oxidative stress by stealing electrons. It was also reported by [35] that, ascorbic acid is a low molecular weight antioxidant that scavenges the ROS through electron transfer rapidly and prevents lipid peroxidation as reported by Flora and Tandon [36].

Furthermore, it has been demonstrated by several studies that vitamin C forms the first line of antioxidant defense and effectively protects the lipid plasma and lipoproteins against detectable per-oxidative damage under many different types of oxidizing conditions [37]. Our result is in agreement with Huang et al. [38] a research work that discovered that dehydroascorbic acid; a blood-brain barrier-transportable form of vitamin C, caused dose-dependent increase in post-reperfusion cerebral blood flow, with reductions in the infarct volume, neurological deficit, and mortality. Also, in the studies by [39-41] it was found that an increase in antioxidant vitamin $\mathrm{C}$ intake resulted in a decreased risk of stroke.

The positive outcome of the vitamin E (VE) treated group of this study compared to SINT group could be connected to the mode of action of vitamin E, VE is a chain breaking antioxidant and it can be transported into neurons and neuronal mitochondria which tolerates VE to take part directly in the regulation of the destruction which is as a result of oxidant stress according to the report by Yagamata et al. [42]. The main mechanism of action of VE is; adding hydrogen to peroxy radicals (ROO $\left.{ }^{\circ}\right)$. Meanwhile, VE can reacts with single oxygen $\left({ }^{1} \mathrm{O}_{2}\right)$ and hydroxyl radicals $\left(\mathrm{HO}^{\circ}\right)$. Because of this, VE is therefore described as an antioxidant known as chain-breaking that blocks reactive oxygen metabolic cascades [43]. Our observation is similar to the report of Inci et al. [44], where vitamin E was observed to modify oxidative stress pathways and improves neurological results in many animal studies, so also, administration of vitamin E cause a neuro-protective effect by decreasing the rate of lipid peroxidation. Again, Carmen and Oyvind [45] reported that vitamin $\mathrm{E}$ is a lipid soluble antioxidant which prevents the formation of lipid peroxide. Because vitamin $\mathrm{E}$ is one of the potent antioxidant, it exert its action in many organs of the body, it can also cross the BBB and accumulates to therapeutic levels in CNS, which in turn may prevent spatial learning deficit as seen in animal model of aging [46], improve cognitive function, as seen in animal model of Alzheimer's with repetitive concussive brain injury and provide neuro-protection from any other types of insults [47].

The effectiveness seen in uric acid (UA) treatment could be attributed to the way uric acid functions as an antioxidant because its protection system includes the use of endogenous antioxidant enzymes (SOD and GPx), vitamin E which is free radical scavengers and $\beta$-carotenes in the cell lipid portion, ascorbic acid and UA in the aqueous phase [48]. UA is a strong free radical scavenger; it can also act as a chelator of metal ions, such as iron and copper, by transforming them to poorly volatile forms. One of the most essential antioxidants in human biological fluids is uric acid [49]. The findings of this study further pointed out the function of UA as an antioxidant and the study is in agreement with the report of Waring et al. [50] where they stated that administration of UA in healthy volunteers with low baseline serum concentrations increased the antioxidant ability [50]. Also, it was reported by Yu et al. [51] that uric acid suppresses the accumulation of ROS and lipid peroxidation following an exposure to glutamate or ischemic injury as it was shown by a confocal laser scanning microscopy [51]. Many studies have demonstrated the importance of UA in the management of stroke; in a study carried out by Amaro et al. [52] it was reported that increase UA levels were associated with an improved rate of excellent recovery independently of baseline variables. Moreover, increased serum levels of UA were significantly associated with smaller infarction volumes [52]. Wu et al. [53] conducted a study on 1351 ischemic and 380 cerebral hemorrhage patients and showed that reduced uric acid levels correlate with poor outcomes in acute ischemic stroke patients, but not in cerebral hemorrhagic patients. Wu et al. [53] stated that high serum of uric acid level is associated with good neurological outcome at the time of hospital discharge in patients with acute ischemic stroke.

ALA showed a promising result in our findings, the mechanism by which ALA improved the status of our ischemic stroke ALA treated group may be because, ALA is a strong thiol antioxidant with the following important mechanisms of action: ROS scavenging capacity, regeneration of endogenous antioxidants particularly endogenous antioxidants that are necessary for repair systems and has a metal chelating capacity as stated by Biewenga et al. [54]. This result is in line with the report of Connell and Saleh [55] 
where they stated that ALA produced a dose-dependent neuro-protection against neuronal cell death as observed in a previously confirmed, novel model of ischemia-reperfusion injury. Also the finding is consistent with the research that demonstrated the beneficial effects of ALA in animals subjected to cerebral ischemia-reperfusion. Such benefits include a decrease in ischemic damage, a decrease in the level of neuronal ROS, and enhanced post-ischemic survival [56]. Our findings are in accordance with the research reported by Choi et al. [57] where it was argued that the possible mechanism by which ALA promotes favorable outcomes may be related to the activation of the insulin receptor; which is a well-known neuro-protectant. In addition, ALA has been reported to be safe and effective in the treatment of IS, from a previous study by Schreibelt et al. [58] ALA has a stabilizing effect on the $\mathrm{BBB}$, making it an attractive therapeutic agent for the treatment of ischemic stroke. Destruction of BBB is a common event in ischemic stroke and is aggravated by reperfusion [59]. Therefore, one of the most important targets for the effective treatment of cerebral ischemia is the protection of the BBB against damage as reported by Choi et al. [60].

It is evident in this study that DMSO group of supplementation improved significantly much more than other treated groups. DMSO is a simple organic compound that has so many biological actions including antioxidant, anti-inflamatory, anti-nociceptive and radio-protective effects as reported by Shigetoshi et al. [61]. In addition, DMSO is a highly soluble substance that distributes throughout the entire body including brain very rapidly [61]. Furthermore, it solubilizes many lipophilic compounds and increases penetration of many drugs into the brain. Accordingly, it is frequently used as a vehicle in pharmacological studies in cerebral ischemia [62]. DMSO treatment resulted in an improved outcome after transient cerebral ischemia measured by MRI and by a functional neuro-score. This study is also in agreement with the work of Bartdutzky et al. [63] where they reported that DMSO has already proven its neuro-protective effects in rats in different doses when administered before and after permanent ischemia of $24 \mathrm{~h}$ and MRI observations showed a persistent diffusion/perfusion mismatch.

Treatment with mannitol significantly increased the activities of antioxidants enzymes and decreased significantly the concentration of oxidative stress marker; MDA when compared with the SINT control group. The observed effect of management could be as a result of anti-edema ability which could also have contributed to antioxidant effect Yilmaz et al. [64]. Reported that early administration of mannitol after head trauma is more effective in reducing oxidative damage and avoiding cellular damage than the antioxidant enzymes, however administration of mannitol and $7.5 \%$ hypertonic saline to reduce intracranial pressure by drawing water from interstitial and intracellular areas to an intravascular area also increases the levels of catalase and GSH-Px enzymes. It has been suggested that these enzymes would reduce the production of MDA, which is a harmful substance for cells and would thereby reduce cellular damage.

\section{Conclusion}

In conclusion, our study on the treatment of ischemic stroke using LMWA for two weeks reveals that there was reduction of activities of antioxidant enzymes and increase in the concentration of oxidative stress biomarker suggesting the presence oxidative stress in the stroke induced non treated (SINT) group. All the antioxidants used in this study increases the antioxidant enzyme activities and reduced the concentration of oxidative stress biomarker following two weeks of treatment. These findings might provide new insights into the understanding of the pathogenesis of ischemic stroke as well as open new therapeutic possibilities.

\section{Acknowledgement}

We thank and appreciate the contributions of scientist Bashir, a member of Chemical Pathology Laboratory, Usmanu Danfodiyo University Teaching Hospital (UDUTH) Sokoto, Nigeria, as well as Mallam Ngaski of the department of Veterinary Physiology and Biochemistry, Faculty of Veterinary Medicine, Usmanu Danfodiyo University Sokoto, Nigeria, for there technical and moral support.

\section{References}

1. WHO (2002) The World Health Report 2002: Reducing Risks, Promoting Healthy Life. World Health Organization, Geneva.

2. Deb P, Sharma S, Hassan KM (2010) Pathophysiologic mechanisms of acute ischemic stroke: an overview with emphasis on therapeutic significance beyond thrombolysis. Pathophysiology 17: 197-218.

3. Suleiman N, Bilbis LS, Saidu Y, Nasiru JI, Dallatu MK, et al. (2015) Effect of some low molecular mass antioxidants in the management of traumatic brain injury in albino rats. Int J Curre Res 7: 18492-9.

4. Candelario-Jalil E (2009) Injury and repair mechanisms in ischemic stroke: considerations for the development of novel neurotherapeutics. Curr Opin Investig Drugs 10: 644-54.

5. Janardhan V, Qureshi AI (2004) Mechanisms of ischemic brain injury. Curre cardiol Rep 6: 117-23.

6. Niizuma K, Endo H, Chan PH (2009) Oxidative stress and mitochondrial dysfunction as determinants of ischemic neuronal death and survival. J Neurochem 109: 133-8.

7. Ames BN, Shigenaga MK, Hagen TM (1993) Oxidants, antioxidants, and the degenerative diseases of aging. Proceedings of the National Academy of Sciences 90: 7915-22.

8. Evans PH (1993) Free radicals in brain metabolism and pathology. Br Med Bull 49: 577-87.

9. Watanabe T, Tanaka M, Watanabe K, Takamatsu Y, Tobe A (2004) Research and development of the free radical scavenger edaravone as a neuroprotectant. J Pharmaceu Soc Japan 124: 99-112.

10. Hall ED, Yonkers PA, McCall JM, Braughler JM (1988) Effects of the 21-aminosteroid U74006F on experimental head injury in mice. J Neurosurg 68: 456-61.

11. Amstad PA, Krupitza G, Cerutti PA (1992) Mechanism of c-fos induction by active oxygen. Cancer Res 52: $3952-60$. 
12. Lander HM, OgisteJS, Teng KK, Novogrodsky A (1995) p21ras as a common signaling target of reactive free radicals and cellular redox stress. J Bio Chem 270: 21195-8.

13. Reiter RJ (1995) Oxidative processes and antioxidative defense mechanisms in the aging brain. The FASEB Journal 9: 526-33.

14. Dekkers JC, van Doornen LJ, Kemper HC (1996) The role of antioxidant vitamins and enzymes in the prevention of exercise-induced muscle damage. Sports Med 21: 213-38

15. Wang X, Mori T, Sumii T, Lo EH (2002) Hemoglobin-induced cytotoxicity in rat cerebral cortical neurons caspase activation and oxidative stress. Stroke 33: 1882-8.

16. Tuladhar AM, de Leeuw FE (2010) Dementia: Post stroke dementia-what's in a name? Nature Reviews Neurology 6: 63-4.

17. Desalu OO, Wahab KW, Fawale B, Olarenwaju TO, Busari OA, et al. (2011) A review of stroke admissions at a tertiary hospital in rural Southwestern Nigeria. Ann Afr Med 10: 80-5.

18. Ogun SA, Ojini FI, Ogungbo B, Kolapo KO, Danesi MA (2002) Stroke in south west Nigeria: A 10-year review. Stroke 36: 1120-2.

19. Ogun SA, Oluwole O, Fatade B, Ogunseyinde AO, Ojini FI, et al. (2002) Comparison of Siriraj Stroke Score and the WHO criteria in the clinical classification of stroke subtypes. Afr J Med Med Sci 31: 13-6.

20. Davis SM, Donnan GA (2012) Secondary prevention after ischemic stroke or transient ischemic attack. New England J Med 366: $1914-22$.

21. Connell B J, Saleh MC, Khan BV, Saleh TM (2011) Apocynin may limit total cell death following cerebral ischemia and reperfusion by enhancing apoptosis. Food Chem Toxicol 49: 3063-9.

22. Fonarow GC, Smith EE, Saver JL, Reeves MJ, Bhatt DL, et al. (2011) Timeliness of tissue-type plasminogen activator therapy in acute ischemic stroke: $\quad$ Patient characteristics, hospital factors, and outcomes associated with door-to-needle times within 60 minutes. Circulation 123: 750-8.

23. Spratt NJ, Fernandez J, Chen M, Rewell S, Cox S, et al. (2006) Modification of the method of thread manufacture improves stroke induction rate and reduces mortality after thread-occlusion of the middle cerebral artery in young or aged rats. J Neurosci Methods 155: 285-90.

24. Chen J, Zhang C, Jiang H, Li Y, Zhang L, et al. (2005) Atorvastatin induction of VEGF and BDNF promotes brain plasticity after stroke in mice. J Cereb Blood Flow Metab 25: 281-90.

25. Jover R, Rodrigo R, Felipo V, Insausti R, Sáez-Valero J, et al. (2006) Brain edema and inflammatory activation in bile duct ligated rats with diet-induced hyperammonemia: A model of hepatic encephalopathy in cirrhosis. Hepatology 43: 1257-66.

26. Baird AL, Meldrum A, Dunnett SB (2001) The staircase test of skilled reaching in mice. Brain Research Bulletin 54: 243-50.

27. Gharbawie OA, Whishaw PA, Whishaw IQ, (2004) The topography of three-dimensional exploration: a new quantification of vertical and horizontal exploration, postural support, and exploratory bouts in the cylinder test. Behav Brain Res 151: 125-35.

28. Keshteli FZ, Parivar K, Joghatayi MT, Beik HA (2014) Study of the differentiation of rat omentum stem cells to nerve cells using brain tissue extract of Wistar rats. Inte J Cell Mol Biotechnol 2014: 1-13.

29. Hossmann KA (1994) Viability thresholds and the penumbra of focal ischemia. Annals of Neurology 36: 557-65.

30. Johansson LH, Borg LA (1988) A spectrophotometric method for determination of catalase activity in small tissue samples. Anal Biochem 174: 331-6.

31. Marklund S (1980) Distribution of CuZn superoxide dismutase and Mn superoxide dismutase in human tissues and extracellular fluids. Acta PhysiolScand Suppl 492: 19-23.

32. Paglia DE, Valentine WN (1967) Studies on the quantitative and qualitative characterization of erythrocyte glutathione peroxidase. J Lab Clin Med 70: $158-69$.

33. Niehans WG, Samuelson BAS (1968) Rapid method for the estimation of malondialdehyde. Eur J Biochem 6: 126-8.

34. Gilgun-Sherki Y, Rosenbaum Z, Melamed E, Offen D (2002) Antioxidant therapy in acute central nervous system injury: Current state. Pharmacological Review 54: 271-84

35. Frei B, England L, Ames BN (1989) Ascorbate is an outstanding antioxidant in human blood plasma. Proceedings of National Academy of Science USA. 86: 6377-81.

36. Flora SJ, Tandon SK (1986) Preventive and therapeutic effects of thiamine, ascorbic acid and their combination in lead intoxication. Acta Pharmacologica et Toxicologica (Copenh) 58: 374-8.

37. Polidori MC, Mecocci P, Frei B(2001) Plasma vitamin C levels are decreased and correlated with brain damage in patients with intracranial hemorrhage or head trauma Stroke 32: 898-902.

38. Huang J, Agus DB, Winfree CJ (2001) Dehydroascorbic acid, a blood brain barrier transportable form of vitamin C, mediates potent cerebroprotection in experimental stroke. Proc Natl Acad Sci USA 98: 11720-4

39. Gey KF, Stahelin HB, Eichholzer M (1993) Poor plasma status of carotene and vitamin C is associated with higher mortality from ischemic heart disease and stroke: Basel Prospective Study. Clin Investig 71: 3-6.

40. Keli SO, Hertog MG, Feskens EJ, Kromhout D (1996) Dietary flavonoids, antioxidant vitamins, and incidence of stroke: The Zutphen study. Arch Intern Med 156: 637-42.

41. Daviglus ML, Orencia AJ, Dyer AR (1997) Dietary vitamin C, betacarotene and 30-year risk of stroke: Results from the Western Electric Study. Neuroepidemiology 16: 69-77.

42. Yamagata K, Tagam M, Yamori Y (2010) Neuronal Vulnerability of stroke-prone spontaneously hypertensive rats to ischemia and its prevention with antioxidants such as vitamin E. Neuroscience 170: 1-7.

43. Chow CK (1991) Vitamin E and oxidative stress. Free Radic Biol Med 11: 215-32.

44. Inci S, Ozcan OE, Kilinic K (1998) Time-level relationship for lipid peroxidation and the protective effect of a-tocopherol in experimental mild and severe brain injury. Neurosurgery 43: 330-5.

45. Ramirez-Tortosa C, Andersen ØM, Cabrita L, Gardner PT, Morrice PC (2001) Anthocyanin-rich extract decreases indices of lipid peroxidation and DNA damage in vitamin E-depleted rats. Free Radic Biol Med 31: 1033-7.

46. Veinberg BH, Mallory M, Sagara Y, Masliah E (2000) Vitamin E supplementation prevents spatial learning deficits and dendritic alterations in aged apolipoprotein E-deficient mice. Eur J Neurosci 12: 4541-6. 
47. Sung S, Yao Y, Uryu K (2004) Early vitamin E supplementation in young but not aged mice reduces abeta levels and amyloid deposition in a transgenic model of Alzheimer's disease. FASEB J 18: 323-5.

48. Watanabe S, Kang DH, Feng L (2002) Uric acid, hominoid evolution and the pathogenesis of salt-sensitivity. Hypertension 40: 355-60.

49. Glantzounis G, Tsimoyiannis E, Kappas A, Galaris D (2005) Uric acid and oxidative stress. Curr Pharm Des 11: 4145-51.

50. Waring WS, Webb DJ, Maxwell SR (2001) Systemic uric acid administration increases serum antioxidant capacity in healthy volunteers. J Cardiovasc Pharmacol 38: 365-71.

51. Yu ZF, Bruce-Keller AJ, Goodman Y, Mattson MP(1998) Uric acid protects neurons against excitotoxic and metabolic insults in cell culture, and against focal ischemic brain injury in vivo. J Neurosci Res 53: 613-25.

52. Amaro S, Urra X, Gómez-Choco M, Obach V, Cervera A, et al. (2011) Uric Acid Levels Are Relevant in Patients With Stroke Treated With Thrombolysis. Stroke 2: S28-32.

53. Wu H, Jia Q, Liu G, Liu L, Pu Y, et al. (2013) Decreased Uric Acid Levels Correlate with Poor Outcomes in Acute Ischemic Stroke Patients, but Not in Cerebral Hemorrhage Patients. J Stroke Cerebrovascul Dis 23: 469-75.

54. Biewenga GP, Haenen GRM, Bast A (1997) The pharmacology of the antioxidant lipoic acid. Gen Pharmacol 29: 315-31.

55. Connell BJ, Saleh TM (2010) A novel rodent model of reperfusion injury following occlusion of the middle cerebral artery. J Neurosci Methods 190: 28-33.

56. Clark WM, Rinker LG, Lessov NS, Lowery SL, Cipolla MJ (2001) Efficacy of antioxidant therapies in transient focal ischemia in mice. Stroke 32: 1000-4.

57. Choi KH, Park MS, Kim HS, Kim KT, Kim HS, et al. (2015) Alpha-lipoic acid treatment is neuro-restorative and promotes functional recovery after stroke in rats. Mol Brain 8: 9.

58. Schreibelt G, Musters RJ, Reijerkerk A, de Groot LR, van derPol SM, et al. (2006) Lipoic acid affects cellular migration into the central nervous system and stabilizes blood-brain barrier integrity. J Immunol 177: 2630-7.

59. Simard JM, Kent TA, Chen M, Tarasov KV, Gerzanich V (2007) Brain oedema in focal ischaemia: molecular pathophysiology and theoretical implications. Lancet Neurol 6: 258-68.

60. Choi KH, Kim HS, Park MS, Kim JT, Kim JH, et al. (2016) Regulation of caveolin-1 expression determines early brain edema after experimental focal cerebral ischemia. Stroke 47: 1336-43.

61. Shigetoshi S, Roger P, Simona S, Grahama H (1997) Dimethyl sulfoxide (DMSO) treatment reduces infarction volume after permanent focal cerebral ischemia in rats. Neuroscience letters 239: 125-7.

62. Simon N, Just G, Sabine H, Solveig H, Humphrey G, et al. (2007) Diphenyleneiodonium and dimethyl sulfoxide for treatment of reperfusion injury in cerebral ischemia of the rat. Brain Res 1132: 210-17.

63. Bardutzky J, Meng X, Bouley J, Duong TQ, Ratan R, et al. (2005) Effects of intravenous dimethyl sulfoxide on ischemia evolution in a rat permanent occlusion model. J Cereb Blood Flow Metab 968-77.

64. Yilmaz N, Dugler H, Kiymaz N, Yilmaz C, Gudu B, et al. (2007) Activity of mannitol and hypertonic saline therapy on the oxidant and antioxidant system during the acute term after traumatic brain injury in rats. Brain Res 1164: 132-5.

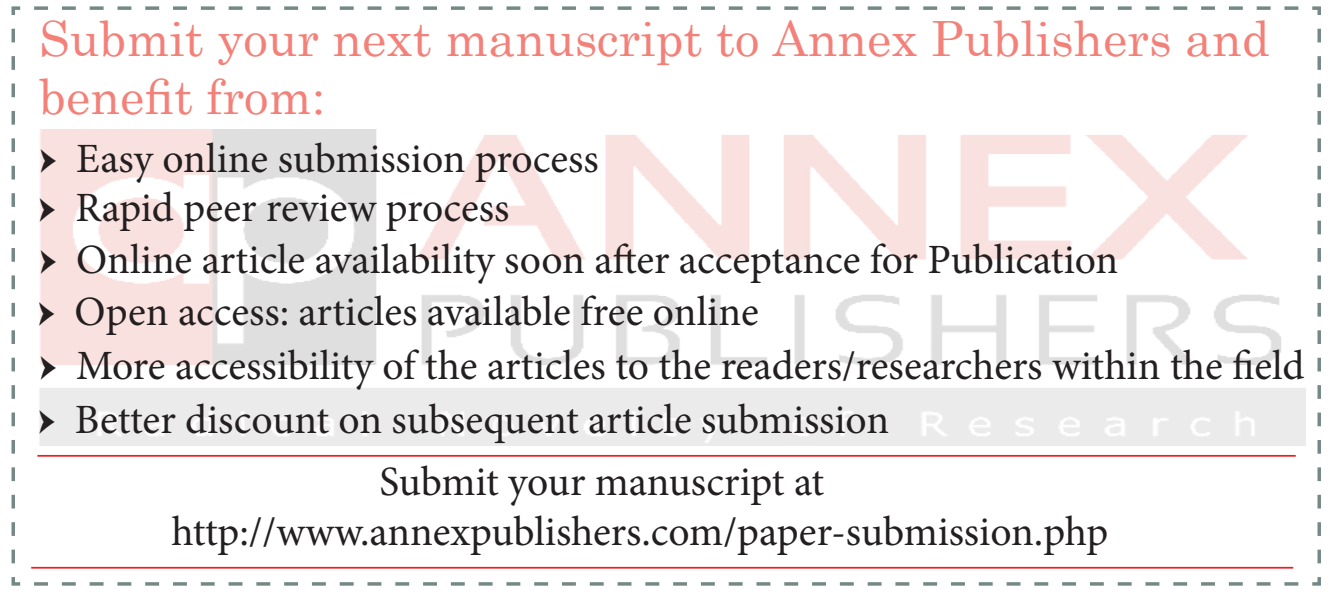

